\title{
Depopulation in Development Areas and the Effect of this upon the Social Environment and Development Policy
}

\author{
MATTI SIPPOLA
}

Balance of the social development comprises balance of the population development. Many other circumstances depend on the population development. When qualitative and quantitative aims for the development policy are set up, the first question to be considered often is the number of the population to which the aims shall apply. By means of the development area policy efforts should be made to regulate the population trend and to influence the factors causing migration. This necessitates proper knowledge of the migration movement, the reasons and aims for it and the effect of it as well on the environment from which the migration emanates as on the environment to which it takes place.

The most distinctive feature of the development areas is a loss of population through migration. In the development area of Finland, the population increased until about the middle of the 1960 's. Since then the population has continuously been decreasing, in the beginning at a slow pace but in the years $1969-1970$ very rapidly. The total population in the development area in 1970 was 2076000 , whereas it was in the year 19652151000 .

However, the change has not been similar within the whole area. In the towns and bigger urban districts the population still has been increasing. Thus only the rural communes have been subjected to the decrease, and different stages can be observed also with regard to these. The decrease of the population generally has started later in the northern parts of the country than in the south. In several communes of southern Finland the population was decreasing already in the 1950's. Within Zone 1 of the development areas the loss of population through migration has been distinctly bigger than within Zone 2 .

\section{The Influence of the Migration on the Social Environment}

One of the most alarming features of the large migration movement is that it principally comprises the young, working and often skilled part of the population. This has brought about quite considerable changes in the structure of the 
population which cannot be considered positive. The share of the young classes previously was in the development area bigger than the average of the whole country. The decrease of the birth-rate within this area has, however, been considerable. The number of children of less than 15 years of age thus proportionally has decreased very much. At the same time the number of old people has been increasing in the whole country. The number of people older than 65 years has proportionally increased most in the northern parts of Finland, whereas the number of people of 50-65 years of age has increased to highest extent in Zone 2 of the development area. As a result of the large decreases within the young age classes the proportional share of the working population has somewhat increased, although the changes in a quantitative sense are not very big.

Also with regard to the sex, the migration has been to some extent of selective character. The women have in this respect been displaying greater activity than the men. As a result of this, the development area has become man-dominated, whereas the population of the towns in the southern part of Finland show a corresponding surplus of women. This proportion is accentuated by the fact that the surplus mainly comprises relatively young women.

In the municipalities, which show a loss of population through migration, there has been a big change in the structure of the economic life. This is partly a reason for the migration and partly a result of same. Manpower has continuously been liberated from farming and forestry, partly because of rationalization of the work, as the farms have become bigger and the mechanization has increased, and partly because the profitability has been decreasing. This liberation of manpower principally has happened in such a way that the children of farmers no longer continue the work of their fathers but move away. There are not enough jobs within other branches to be found in the home locality.

Because of rationalization the possibilities to extra earnings also are decreasing. This has been of significance for the subsistence of the small farmers. The mechanization of forest work has especially been felt by them. As their training often is on a low level and they mostly already are elderly, these people in many cases cannot migrate.

As a result of all this the income level of the population, which is staying on within the development areas, is a low one and consequently the tax income of the municipality is small. It is then necessary to raise the tax unit. A heavy tax burden again is not apt to attract new enterprises to settle in the locality. The municipalities, therefore, can use their tax income only for the most essential demands. Many services relating to sparetime occupation and other activities are suffering because of this. In sum: Those who pay the highest tax, receive the smallest compensation in return. Especially the young people have found the lack of service cheerless, and this has been apt to stimulate migration. The older part of the population has more easily rested content with the most necessary services as public health and other social services. 
As a result of the depopulation, the profitability of many services decreases and the services, therefore, have to be discontinued. In the last few years several hundred service points of the retail trade have closed down. Many elementary schools have also been compelled to discontinue their activities. Eecause of these circumstances the feeling of affinity within a village has weakened. Together with the elementary school the inhabitants of the village have lost their mutual meeting place. The village shop also has been of significance for the contact between the inhabitants. The village no longer is the same entirety as it used to be. The drives to and from school, which have substituted the schools, have made it easier for the children to set themselves free from their own village, and it is no longer difficult for them to move away later on. The elementary school teacher and the shopkeeper also have been prominent persons in the village. When they move away, they leave a great blank behind them.

\section{Development Area Policy and the Means of same}

Development area policy has been exercised in Finland since 1966, when the first laws on development areas were instituted. It is true that some measures also earlier were taken in the least developed areas, but these were only meant as a solution of certain separate problems. The development political measures have been aiming at securing the subsistence of the population and to improve also in other ways the possibilities to live in the development areas. The measures taken hitherto primarily have been of economic political character and have mostly concerned the industry or business nearly related to same. The purpose has been to influence with these means some important factors which regulate the migration movement.

The first laws on development areas were in force during the years 19661969. They comprise laws on tax relief, investment credits and interest subsidy. From a demographic point of view these laws are of interest as far as they have effect on the employment. With the help of the first laws on development areas, about 10000 new jobs were created. According to information received from the enterprises, more than 7500 of these jobs ensued in Zone 1 of the development area. A part of these employments would probably have been created also without the development area benefits. According to calculations made, the number of permanent employments would have been about 4000 lower without these special benefits. This number is about a third of all the employments within the industry created in the development areas during the said period.

The present laws on development areas came into force in the beginning of the year 1970. In the main they are similar to the previous laws. In this connection the boundaries between the development areas were adjusted, and this resulted in a considerable increase of the Zone 1. This area now comprises 
the provinces of Lapland and North Carelia and half of Oulu Province. The southern boundary of Zone 2 goes south of the provinces of Mikkeli and Central Finland to north Satakunta. The Åland islands and the archipelago of Turku also belong to the development areas. No information on the effects of these laws is yet available.

In addition to the actual laws on development areas, some other measures have later been taken for the benefit of these regions. In 1971 the Area Development Fund was set up. The Fund has been granting credit to enterprises within the development areas without claiming securities of the kind ordinary banks demand. The Fund also has granted financing for other activity, which aims at improving the economic life in the development regions, as for instance, research work. The Area Development Fund has to considerable extent improved the possibilities for enterprises of the region to obtain capital.

In the beginning of June the law on transport subsidies took effect. The purpose of this law also is to give support to the business activities within the development area. It provides possibilities to compensate the high costs of transport caused by the long distances.

As a measure, which especially would affect the manpower, a so-called manpower subsidy has been suggested lately. This would compensate an enterprise for the costs it eventually suffers as a result of the use of new and inexperienced labour. In this way it will be easier for an enterprise to get started in a new locality. This subsidy too is thus in the first place granted to enterprises. The indirect effect of this upon the population and its location is, however, greater than that of other measures concerning development regions. The other measures generally have been aimed at supply of capital and they thus have favoured the capital intensive industry to a greater extent than manpower intensive industry.

The entire legislation on development regions is now being renewed. The aim is to enlarge the field of the measures concerning development regions and to increase the effectiveness of the measures. Better utilization than hitherto of the regional resources and possibilities is also strived for. Special efforts are made in order to secure employment, to regulate the scatter of the population and to improve the availability of services.

The body of the new laws will still consist of laws aiming at improvement of the conditions for the activity of enterprises. The group of those to be entitled to the subsidy will, however, be enlargened. It will comprise also farming and forestry and service trades. Efforts are made to develop the economic life in the development regions also by other means than by financing methods concentrated to the production. Measures are, for instance, taken in order to increase the advisory service, information activities and the training. Also such measures, which would be aiming at creation of communities and improvement of the possibilities of municipal activity, have been considered.

At present the development regions are divided into two zones. In connection with the new laws, growth centre policy and policy for sparsely populated 
areas are planned in addition to the division into zones. Within the development regions will be classified centres of different level, which will be subject to differentiated measures. In the developing of a optimum and well-adapted network of centres are used decentralization of state offices and institutions, steering of the regional location of industry and development of services. The purpose is to create population centres, which would be able to entice the population moving away from the rural environment to settle down in these centres.

The aim of the policy concerning sparsely populated areas is to improve the circumstances of the population and to regulate the migration. The intention is also to improve the availability of services by furthering the distribution of them and the mobility of the population. As already said, the measures concerning development areas primarily affect the economic life and its conditions. These measures, however, influence in a considerable way the scatter of the population and the steering of the migration. Labour exchange and allowances for moving expenses also have had a certain effect. However, further social development measures are needed. The goal which should be reached is that the special conditions of the development regions should be considered in all provisions which are instituted. The housing production is very important, because it has a great influence on the location of the population. Measures which are apt to cause unemployment or to liberate at one time a considerable part of the population from its previous occupation should be avoided.

Measures for which the development areas are the sole object will not, however, be sufficient in order to control the migration. It has been noted that the primary factor determining the direction of the migration is the attraction exerted by the receiving localities. If the attraction of the Helsinki region will remain unchanged, the effect of minor growth centre political measures will not be of much significance. Restrictive measures are needed in the crowded areas. Those are in Finland at present only the Helsinki region and its neighbouring communes.

When the policy is changed to one covering crowded regions, also the regions lying between the crowded region and the development regions must be considered at the same time. Therefore, regional policies extended to cover the whole country should be adapted. This is also the goal for the plans made out in order to fix the regional objectives for economic life and population. The regional planning organs clearly show a great willingness to contribute to the creation of national development plans.

The population is a very central element in the planning. Generally the development of the population is stated as cause for the dimensioning of functions and for the development of the social structure. The more concrete the efforts to attain certain regional goals are, the more necessary it becomes to put up population goals. For a well-balanced development also regulation of the migration is necessary. Too rapid changes cause difficulties as well within the locality which is being left as within the receiving locality. 
A strong centralization of the population causes crowded area and pollution problems. In the areas of depopulation, certain waste is emanating because infrastructure and other resources are not being utilized. Within the crowded areas it would, therefore, be necessary to bring about a population roof, which the number of the population should not be allowed to exceed, and within the areas of depopulation corresponding minimum numbers, at which the population at least should be maintained. 